\title{
In Vitro Metabolic Stability and Permeability of Gymnemagenin and Its In Vivo Pharmacokinetic Correlation in Rats - A Pilot Study
}

Authors

Affiliations
Rammohan Bera ${ }^{1}$, Amit Kundu ${ }^{1}$, Tuhinadri Sen ${ }^{1}$, Dipan Adhikari ${ }^{2}$, Sanmoy Karmakar ${ }^{1,3}$

${ }^{1}$ Division of Pharmacology, Department of Pharmaceutical Technology, Jadavpur University, Kolkata, India

2 Department of Botany, Hooghly Mohsin College, Chinsurah, Hooghly, West Bengal, India

${ }^{3}$ Bioequivalence Study Centre, Department of Pharmaceutical Technology, Jadavpur University, Kolkata, India

\author{
Key words \\ - Gymnema sylvestre \\ - Asclepiadaceae \\ - gymnemagenin \\ - rlm \\ - Caco-2 \\ - pharmacokinetics \\ - LC-MS/MS
}

received August 27, 2015

revised Dec. 12, 2015

accepted Dec. 18, 2015

Bibliography

DOI http://dx.doi.org/

10.1055/s-0042-101032

Published online February 25,

2016

Planta Med 2016; 82: 544-550

(c) Georg Thieme Verlag KG

Stuttgart · New York .

ISSN 0032-0943

\section{Correspondence}

\section{Sanmoy Karmakar}

Division of Pharmacology

Department of Pharmaceutical

Technology

Jadavpur University

188-Raja SC Mallick Road

Kolkata - 700032

India

Phone: + 9194343749

sanmoykarmakar@gmail.com

\section{Abstract \\ $\nabla$}

Gymnema sylvestre is traditionally used for diabetes mellitus. A literature survey revealed very few reports, particularly on rat liver microsomal stability, caco- 2 permeability and efflux concerns and its correlation with the bioavailability of gymnemagenin, an important component of $G$. sylvestre. Therefore, the objective of our study was to investigate the in vitro rat liver microsomal stability and caco-2 permeability along with the efflux of gymnemagenin and establish a probable correlation of these in vitro findings with pharmacokinetic parameters after oral and intravenous administration in rats.

Rat liver microsomal stability studies to estimate the in vitro intrinsic half-life, clearance, and $\mathrm{Ca}$ co-2 permeability after 21 days of culture to determine the apparent permeability from apical to basal and from basal to apical, and efflux ratio of gymnemagenin were performed using liquid chromatography-tandem mass spectrometry. A sensitive, robust bioanalytical method was validated and successfully applied to determine the plasma exposure of gymnemagenin.

In vitro rat liver microsomal stability demonstrated that gymnemagenin metabolizes rapidly with a short apparent and intrinsic half-life $(\sim 7 \mathrm{~min})$ and high intrinsic clearance, i.e., $190.08 \mu \mathrm{L} / \mathrm{min} /$ $\mathrm{mg}$ of microsomes. The results of the Caco-2 study indicated a poor permeability (1.31× $10^{-6} \mathrm{~cm} / \mathrm{sec}$ ) with a very high efflux ratio. The

\section{Introduction}

\section{$\nabla$}

Gymnema sylvestre (Retz.) Schult. (Apocynaceae; syn. Periploca sylvestris Retz.) is a traditionally used medicinal plant with reported use as a remedy for diabetes mellitus and stomachic and diuretic problems. The plant extract is also used in folk, Ayurvedic, and homeopathic systems of pharmacokinetic study revealed poor oral bioavailability $(\sim 14 \%)$ of gymnemagenin and it was found to have a short half-life and a high clearance in rats. Our in vitro findings indicated low metabolic stability and poor Caco-2 permeability with high efflux, which might have a role in the observed poor oral bioavailability in rats.

\section{Abbreviations}

$\nabla$

AUC: $\quad$ area under the curve

$\mathrm{CL}_{\mathrm{app} \text {,int }}$ apparent/intrinsic clearance

EfR: efflux ratio

GG: gymnemagenin

IS: internal standard

IV: $\quad$ intravenous

LC-MS/MS: liquid chromatography-tandem mass spectrometry

LY: lucifer yellow

NADP: nicotinamide adenine dinucleotide phosphate

NRS: $\quad$ reduced NADP regenerating system

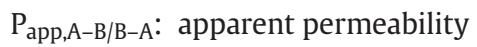

(apical to basal/basal to apical)

P-gp: $\quad$ permeability glycoprotein

QC: $\quad$ quality control

RLM: $\quad$ rat liver microsomes

Supporting information available online at http://www.thieme-connect.de/products medicine [1]. G. sylvestre occurs mainly in the Deccan peninsula of western India, Tropical Africa, Vietnam, Malaysia, and Srilanka and is widely available in Japan, Germany, and the USA as a health food [2]. In the last 10 years, several products under brand names such as Body Slatto Tea ${ }^{\circledR}$, Gymnema ${ }^{\circledR}$, Gymnema Diet $^{\circledR}$, Sugar Off ${ }^{\circledR}$, Glucoset $^{\circledR}$, Cinndrome $X^{\circledR}$, and Pilisoft ${ }^{\circledR}$ have 
flooded the global markets as health foods and cosmetics [3]. Gymnemic acid and GG are believed to be the major active compounds of G. sylvestre, and GG, which enters the circulation after hydrolysis of gymnemic acids, is a common genin for most of the gymnemic acids [4-6].

It has been a clinical concern that herbal products containing a number of natural compounds can cause pharmacokinetic interactions with modern medicines, particularly in combination. Therefore, detailed studies of the commonly consumed herbal products with a particular interest to safety and related pharmacokinetics need to be done. Among these issues the pharmacokinetic parameter for herbal products having numerous components can probably be addressed with the help of phytomarker as a representative molecule. So far, only a few programs have been established to study the pharmacokinetics and pharmacodynamics of herbal medicines, as was originally proposed by the WHO Guidelines for the assessment of herbal medicines.

Evaluation of in vitro pharmacokinetic properties has become mandatory in industrial drug discovery research to speed up the discovery process, reduce the failure rate at the final stage, minimize time and cost, and guide medicinal chemists to modify the compound's structures to get pharmacokinetically acceptable compounds [7]. Usually by using the "in vitro $\mathrm{T}_{1 / 2}$ method", $\mathrm{CL}_{\mathrm{app} \text {,int }}$ is determined by measuring the first order rate constant for consumption of the substrate at a low concentration. This preclinical in vitro drug metabolism data is considered to have a good correlation with in vivo pharmacokinetics data, which is further used to predict human pharmacokinetic parameters [8]. Evaluation of the drug transport mechanism is becoming increasingly important in drug delivery and pharmacokinetics research. Thus, the Caco-2 cell monolayer has a lot of importance as a reliable and high-throughput in vitro model to evaluate intestinal passive permeability as well as P-gp efflux. P-gp has been identified in rats and human tissue such as the intestines, liver, brain, and kidneys, suggesting that P-gp function may contribute to drug absorption, distribution, and elimination [9]. For orally administered compounds, permeability through the Caco- 2 cell monolayer correlates well with in vivo absorption in humans [10,11].

A comprehensive knowledge of in vitro pharmacokinetics, permeability, the role of P-gp, and their correlation with the in vivo data of GG is important for the interpretation of the pharmacology and toxicology of this herb, G. sylvestre, and its different formulations containing the same.

In the present work, the oral bioavailability of GG in terms of Caco-2 permeability $\left(\mathrm{P}_{\mathrm{app}, \mathrm{A}-\mathrm{B}}\right)$ and the $\mathrm{P}$-gp efflux ratio $\left(\mathrm{P}_{\mathrm{app}, \mathrm{B}-\mathrm{A}}\right)$ $\left.\mathrm{P}_{\mathrm{app}, \mathrm{A}-\mathrm{B}}\right)$ was studied after 21 days of cell culture. The in vitro intrinsic half-life $\left(\mathrm{T}_{1 / 2 \text {,int }}\right)$ and apparent intrinsic clearance ( $\left.\mathrm{CL}_{\text {int,app }}\right)$ of GG was also measured after incubation with RLM at $37.5^{\circ} \mathrm{C}$. Finally, attempts were made to develop a simple, sensitive, and robust LC-MS/MS method, and our method is believed to be advantageous compared with previously published methods [12] and has been validated according to the US Food and Drug Administration's Guidance for Industry [13] for the determination and quantification of GG in rat plasma following a single oral dose and intravenous administration of GG using dexamethasone as an internal standard, and finding a correlation of WinNonlin calculated pharmacokinetic parameters.

\section{Results}

7

In positive electrospray ionization, GG and dexamethasone showed intense $\mathrm{Q} 1[\mathrm{M}+\mathrm{H}]^{+}$ions at $\mathrm{m} / \mathrm{z} 507.4$ and 393.2, respectively. The daughter ions were at $m / z 471.4$ and 147.2 and observed after fragmentation for GG and IS, respectively, which were monitored in MRM (multiple reaction monitoring) to quantify GG in the plasma. The linear equation of the standard curve was obtained by regressional analysis of the peak area ratio of analyte to internal standard versus nominal concentration with a weighting factor of $1 / \mathrm{x}^{2}$. The calibration curve was linear in the concentration range of $0.98-1000.00 \mathrm{ng} / \mathrm{mL}$ with an average regression coefficient, slope, and intercept of $0.9974 \pm 0.0014$, $0.0011 \pm 0.00004$, and $0.0004 \pm 0.00003$, respectively.

The back-calculated concentration values for all QCs run in six triplicates at each concentration level, i.e., lower limit of quantitation (LLOQ, $0.98 \mathrm{ng} / \mathrm{mL}$ ), lower quality control (LQC, $2.94 \mathrm{ng} / \mathrm{mL}$ ), medium quality control (MQC, $400 \mathrm{ng} / \mathrm{mL}$ ), and higher quality control (HQC, $800 \mathrm{ng} / \mathrm{mL}$ ) on three different occasions, were used to assess the accuracy and precision of the method. The inter-run and intra-run precision and accuracy for the various concentrations ranged from $1.76-6.75 \%$ and $97.74-106.75 \%$, and $3.11-$ $5.57 \%$ and $98.74-103.87 \%$, respectively. The mean extraction recovery and matrix effect in the plasma at the LQC, MQC, and HQC levels were $87.41 \%, 98.81 \%$, and $90.52 \%$, and $2.76 \%, 3.67 \%$, and $3.06 \%$, respectively.

All the QC samples stored at $-70^{\circ} \mathrm{C}$ were found to be stable for at least one month. The back calculated concentration values for all QC samples at each concentration level after $24 \mathrm{~h}$ in the autosampler at $4^{\circ} \mathrm{C}$ as well as the plasma samples standing at room temperature for $8 \mathrm{~h}$ and three freeze-thaw cycles of GG showed a good accuracy (92.86-104.43\%), which indicated that the compound was stable in specified conditions in the rat plasma.

In the RLM stability study, there was a 60 min sample without a cofactor for the test and QC samples to determine non-metabolic degradation. The parent area detected in $\mathrm{T}=60 \mathrm{~min}$ without cofactor samples by LC-MS/MS for GG, desipramine, metoprolol, and verapamil was comparable to the $\mathrm{T}=0 \mathrm{~min}$ sample. This indicated that GG, desipramine, metoprolol, and verapamil did not

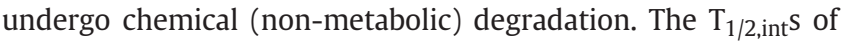
GG, desipramine, metoprolol, and verapamil were $7.31 \pm 0.51$, $5.87 \pm 0.54,37.57 \pm 1.53$, and $4.26 \pm 0.13 \mathrm{~min}$, respectively, and the $\mathrm{CL}_{\text {int,app }} \mathrm{S}$ were $190.08 \pm 13.01,237.33 \pm 22.48,36.93 \pm 1.50$, and $325.33 \pm 10.07 \mu \mathrm{L} / \mathrm{min} / \mathrm{mg}$ of protein, respectively [14] ( $\odot \mathrm{Ta}$ ble 1 ).

Atenolol is a low permeable compound without efflux and is transported by passive diffusion. Furosemide is also a low permeable compound with a high efflux ratio and a transporter(s) is involved for permeation through the Caco-2 cell monolayer. Carbamazepine is transported by passive diffusion due to it having high permeability, whereas verapamil also belongs to the high permeable group, but blocks P-gp with an efflux ratio $>2$. So, considering the permeability rank and efflux ratio, the above compounds were selected for Caco-2 as quality controls.

The $\mathrm{P}_{\text {app }}$ values across the Caco- 2 cell monolayer for A to B of GG, atenolol, furosemide, carbamazepine, and verapamil were determined. In this study, the $\mathrm{P}_{\mathrm{app}}$ for QC compounds as well as the permeability rank were comparable with the literature values $[10,15-17]$. The permeability rank of the test and QC compounds were done according to "low", if $\mathrm{P}_{\mathrm{app}}<2.5 \times 10^{-6} \mathrm{~cm} / \mathrm{sec}$, and 


\begin{tabular}{|llll|}
\hline Compound & Intrinsic $\mathbf{T}_{\mathbf{1 / 2 , \text { int }}}(\mathbf{m i n})$ & In vitro $\mathbf{C L}_{\text {int,app }}(\boldsymbol{\mu L} / \mathbf{m i n} / \mathbf{m g})$ & In vivo scaled $\mathbf{C L}_{\text {int }}(\mathbf{L} / \mathbf{h} / \mathbf{k g})$ \\
\hline Gymnemagenin & $7.31 \pm 0.51$ & $190.08 \pm 13.01$ & $24.12 \pm 1.65$ \\
\hline Desipramine & $5.87 \pm 0.54$ & $237.33 \pm 22.48$ & $30.11 \pm 2.83$ \\
\hline Metoprolol & $37.57 \pm 1.53$ & $36.93 \pm 1.50$ & $4.76 \pm 0.16$ \\
\hline Verapamil & $4.26 \pm 0.13$ & $325.33 \pm 10.07$ & $41.59 \pm 1.27$ \\
\hline
\end{tabular}

Table 1 Summary of observed intrinsic half-life and in vitro clearance in rat liver microsomes along with scaled in vivo clearance.

\begin{tabular}{|c|c|c|c|c|}
\hline \multirow[t]{2}{*}{ Compound } & \multicolumn{3}{|c|}{ Avg $P_{\text {app }} \times 10^{-6} \mathrm{~cm} / \mathrm{sec} ; \mathrm{n}=6$} & \multirow[t]{2}{*}{ Permeability rank } \\
\hline & A to $B$ & B to $A$ & Ratio & \\
\hline Gymnemagenin & $1.31 \pm 0.19$ & $31.89 \pm 0.76$ & $24.49 \pm 3.05$ & Low \\
\hline Furosemide & $0.07 \pm 0.02$ & $11.68 \pm 0.24$ & $167.71 \pm 16.94$ & Low \\
\hline Atenolol & $0.31 \pm 0.05$ & ND & ND & Low \\
\hline Verapamil & $9.02 \pm 0.44$ & $63.34 \pm 8.91$ & $7.03 \pm 0.34$ & High \\
\hline Carbamazepine & $33.34 \pm 1.49$ & $40.10 \pm 1.58$ & $1.20 \pm 0.05$ & High \\
\hline Domperidone & $2.56 \pm 0.12$ & $50.14 \pm 3.15$ & $18.90 \pm 0.31$ & High \\
\hline Quinidine & $4.03 \pm 0.21$ & $32.28 \pm 2.57$ & $8.02 \pm 0.11$ & High \\
\hline
\end{tabular}

Table 2 Caco-2 permeability (A to $B$ and $B$ to $A$ ) and P-gp efflux ratio of GG. "high", if $\mathrm{P}_{\mathrm{app}} \geq 2.50 \times 10^{-6} \mathrm{~cm} / \mathrm{sec}$. The $\mathrm{P}_{\mathrm{app}, \mathrm{A}-\mathrm{B}}$ and $\mathrm{P}_{\mathrm{app}, \mathrm{B}-\mathrm{A}}$ were determined based on the following equation [14]:

$\mathrm{P}_{\mathrm{app}}=\left[\mathrm{V}_{\mathrm{a}} /(\right.$ area $\times$ time $\left.)\right] \times($ area of acceptor well/area of donor $)$

where $\mathrm{V}_{\mathrm{a}}=$ volume of acceptor well (in $\left.\mathrm{mL}\right)=0.25$, area $=$ surface area of the membrane $\left(\mathrm{cm}^{2}\right)=0.0804$, and time = time of incubation (seconds) $=9000$.

The EfR, or the ratio of effective permeability for a drug, was calculated based on the following equation:

$\mathrm{EfR}=\left(\mathrm{P}_{\mathrm{app}, \mathrm{B}-\mathrm{A}} / \mathrm{P}_{\mathrm{app}, \mathrm{A}-\mathrm{B}}\right)$

It was found that GG showed poor permeability $(1.31 \pm 0.19 \times 10$

$\left.{ }^{-6} \mathrm{~cm} / \mathrm{sec}\right)$ across $A$ to $B$ and a high $\mathrm{P}_{\text {app,B-A }}\left(31.89 \pm 0.76 \times 10^{-6}\right)$ with a high EfR $24.49 \pm 3.05$. The permeability values along with the efflux ratios of GG, atenolol, carbamazepine, verapamil, domperidon, and quinidine are presented in $\bullet$ Table 2 .

A significant increase of the TEER value was observed during the cell culture, indicating a good integrity of the Caco-2 cell monolayer. A little increase in the TEER value $\left(328.67 \pm 11.56 \Omega \mathrm{cm}^{2}\right)$ was found between days 15 and 20. Assessment of the integrity of the Caco-2 cell monolayer was also determined by the LY permeability test using a fluorescence measurement. If the $\mathrm{P}_{\text {app }}$ of LY exceeds $1 \times 10^{-6} \mathrm{~cm} / \mathrm{sec}$, then it is assumed that the integrity of the Caco- 2 cell monolayer has been improper and the test compound will be retested by another experiment. Wells having more than $1 \%$ fluorescence intensity with respect to $0.1 \mathrm{mg} / \mathrm{mL}$ of the initial donor solution of LY were not considered for the permeability calculation because of poor membrane integrity.

Different pharmacokinetic parameters were determined by noncompartmental analysis using WinNonlin 6.3 from plasma concentration versus time profile for oral and IV administration at 5 and $1 \mathrm{mg} / \mathrm{kg}$ dose, respectively ( Fig. 1 ). The results of the pharmacokinetic study revealed poor oral bioavailability (14.18 \pm $2.38 \%$ ) of GG with a $C_{\max }$ of $45.91 \pm 5.89 \mathrm{ng} / \mathrm{mL}$ and a $\mathrm{T}_{\max }$ of $0.44 \pm 0.13 \mathrm{~h}$ following oral administration. GG showed short terminal half-lives $\left(\mathrm{T}_{1 / 2}\right)$ of $0.41 \pm 0.03$ and $1.33 \pm 0.12 \mathrm{~h}$ following IV and oral administration, respectively. It was also observed that GG is rapidly metabolized and quickly eliminated from the body with a high clearance $(\mathrm{CL})$ of $53.49 \pm 9.23$ and $7.49 \pm 0.81 \mathrm{~L} / \mathrm{kg} / \mathrm{h}$, while the total exposure $\left(\mathrm{AUC}_{0-\alpha}\right)$ was found to be $95.53 \pm$ $16.02 \mathrm{ng} . \mathrm{h} / \mathrm{mL}$ and $134.74 \pm 15.77 \mathrm{ng} \times \mathrm{h} / \mathrm{mL}$ after oral and IV administration, respectively ( $\odot$ Table 3 ). For IV and PO, the plasma

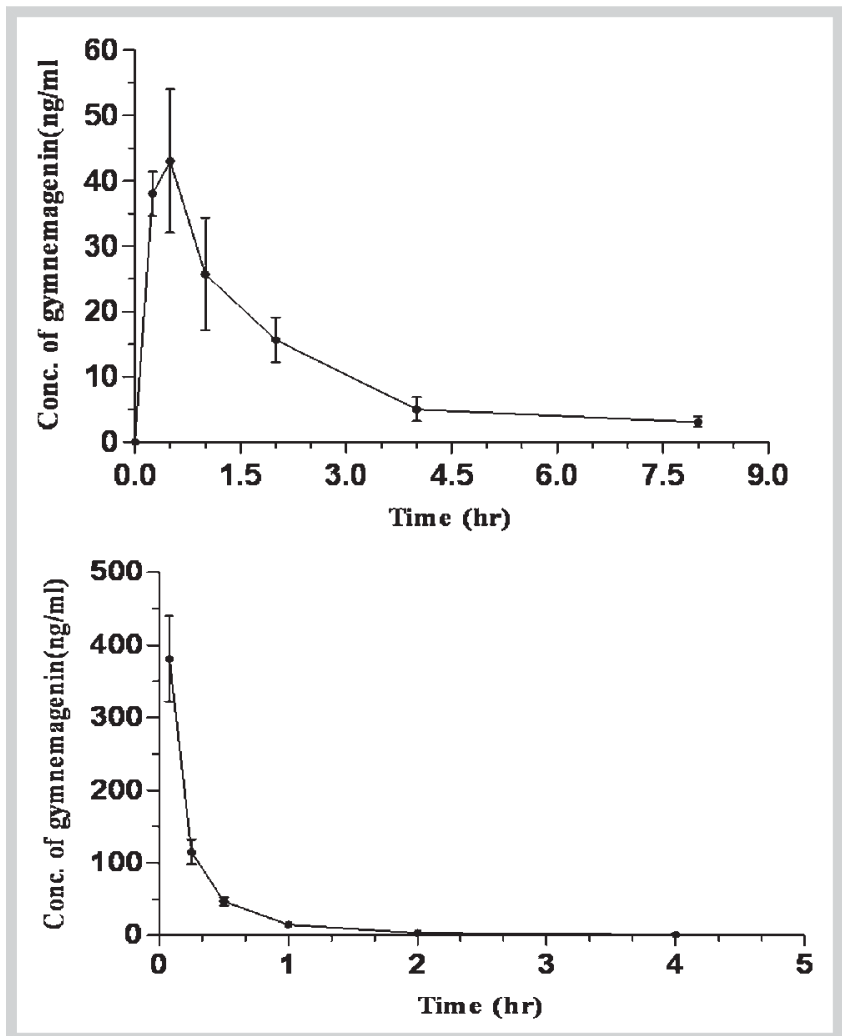

Fig. 1 Mean \pm SD plasma exposure profile of GG following oral and IV administration at $5 \mathrm{mg} / \mathrm{kg}$ and $1 \mathrm{mg} / \mathrm{kg}$, respectively, in rats.

exposure beyond $4 \mathrm{~h}$ and $8 \mathrm{~h}$, respectively, was below quantitation levels.

\section{Discussion \\ $\nabla$}

G. sylvestre is a potent antidiabetic herb that is used for many polyherbal formulations. Gymnemic acid as well as GG are the two major phytoconstituents having antidiabetic activity [4] and are the most accepted phytomarkers used for characterization as well as validation of $G$. sylvestre. Although G. sylvestre is a clinically well-accepted herb, correlation of its RLM stability, Caco-2 per- 
Table 3 Evaluation of pharmacokinetic parameters of GG following IV and oral administration.

\begin{tabular}{|lll|}
$\begin{array}{l}\text { Route-dose } \\
\text { Pharmacokinetic } \\
\text { parameters }\end{array}$ & $\begin{array}{l}\text { IV } \mathbf{- 1} \mathbf{~ m g} / \mathbf{k g}(\mathbf{n}=\mathbf{6}) \\
\text { Mean } \pm \mathbf{S D}\end{array}$ & $\begin{array}{l}\text { PO }-\mathbf{5} \mathbf{~ m g} / \mathbf{k g}(\mathbf{n}=\mathbf{6}) \\
\text { Mean } \pm \text { SD }\end{array}$ \\
\hline $\mathrm{AUC}_{(0-\mathrm{t})}(\mathrm{ng} \times \mathrm{h} / \mathrm{mL})$ & $134.09 \pm 15.78$ & $89.65 \pm 14.90$ \\
\hline $\mathrm{AUC}_{(0-\mathrm{\alpha})}(\mathrm{ng} \times \mathrm{h} / \mathrm{mL})$ & $134.74 \pm 15.77$ & $95.53 \pm 16.02$ \\
$\mathrm{C}_{\max }(\mathrm{ng} / \mathrm{mL})$ & $\mathrm{NA}$ & $45.91 \pm 5.89$ \\
\hline $\mathrm{T}_{\max }(\mathrm{h})$ & $\mathrm{NA}$ & $0.44 \pm 0.13$ \\
\hline $\mathrm{K}_{\mathrm{el}}\left(\mathrm{h}^{-1}\right)$ & $1.71 \pm 0.12$ & $0.52 \pm 0.04$ \\
\hline $\mathrm{T}_{1 / 2}(\mathrm{~h})$ & $0.41 \pm 0.03$ & $1.33 \pm 0.12$ \\
\hline $\mathrm{CL}(\mathrm{L} / \mathrm{h} / \mathrm{kg})$ & $7.49 \pm 0.81$ & $53.49 \pm 9.23$ \\
\hline $\mathrm{Vd}(\mathrm{L} / \mathrm{kg})$ & $1.53 \pm 0.31$ & $\mathrm{ND}$ \\
\hline$\% \mathrm{~F}$ & - & $14.18 \pm 2.38$ \\
\hline
\end{tabular}

$\mathrm{K}_{\mathrm{el}}$ : terminal rate of elimination; NA: not applicable; ND: not determined; $\mathrm{V}_{\mathrm{d}}$ : volume of distribution

meability, and efflux with its bioavailability following oral and IV administration of GG in rats is yet to be investigated.

The aim of the in vitro kinetic study was to determine the in vitro $\mathrm{CL}_{\text {int }}$ by the substrate depletion approach, since formal kinetic characterization and quantification of the specific metabolites are not required [18]. Accordingly, the in vitro intrinsic half-life and clearance were found to be $7.31 \pm 0.51 \mathrm{~min}$ and $190.08 \pm$ $13.01 \mu \mathrm{L} / \mathrm{min} / \mathrm{mg}$ of protein, respectively. The $\mathrm{CL}_{\text {int }}$ was calculated based on the dose $/ \mathrm{AUC}_{0 \text {-inf }}$ instead of the more rigorous approach using enzyme kinetics data that consider maximum enzyme velocity, $\mathrm{V}_{\max }$, and $\mathrm{K}_{\mathrm{m}}$. This simplified approach is probably more appropriate and sophisticated, since the substrate concentration $(1 \mu \mathrm{M})$ is much below the apparent $\mathrm{K}_{\mathrm{m}}$ for substrate turnover and thus no significant product inhibition- or mechanismbased inactivation of the enzyme can be expected [19]. To determine assay specificity and enzyme activity, verapamil, desipramine, and metoprolol were used as quality control samples that have a range of $\mathrm{CL}_{\text {int,app }}$ from 30 to $350 \mu \mathrm{L} / \mathrm{min} / \mathrm{mg}$ of protein [14]. From our in vitro enzyme kinetic studies, it was found that GG is rapidly metabolized by the hepatic oxidative enzyme(s), which indicates that the liver is the major organ of clearance for GG. This rate of metabolism and enzyme activities on GG are truly reflected in rat in vivo pharmacokinetic studies, where we have observed GG to be a poorly bioavailable (\% F 14) compound with short terminal half-lives $0.41 \mathrm{~h}$ and $1.33 \mathrm{~h}$ following IV and oral administration, respectively.

The purpose of our transport study in the Caco-2 monolayer is to rank the test item GG based on $\mathrm{P}_{\mathrm{app}, \mathrm{A}-\mathrm{B}}$ and ascertain whether the test compound is a substrate of the efflux transporter. These data can well be considered to influence oral bioavailability of GG in rats. Generally, an EfR value of $<1.20$ or 1.50 indicates a mere involvement of passive diffusion for drug transportation, whereas an EfR value exceeding unity suggests that the compound may be a substrate of efflux transporters at the apical membrane [20, 21]. In our study, it was observed that $G G$ has poor $A$ to $B$ permeability, $1.31 \times 10^{-6} \mathrm{~cm} / \mathrm{sec}$, and high $B$ to $A$ permeability, $31.89 \times 10^{-6} \mathrm{~cm} / \mathrm{sec}$, with a high EfR of 24.49 . Low Caco- 2 permeability with a high EfR is expected to render a poor systemic exposure of GG. Accordingly, to confirm the abovementioned in vitro enzyme kinetic findings and Caco-2 results, we have performed an oral and IV pharmacokinetic study of GG in rats.

The results of the pharmacokinetic study revealed poor systemic exposure with less than $15 \%$ oral bioavailability and a mean $C_{\max }$, of $45.91 \mathrm{ng} / \mathrm{mL}$ achieved within half an hour following oral administration. GG showed short terminal half-lives of less than $0.5 \mathrm{~h}$ and $1.33 \mathrm{~h}$ following IV and oral administration, respectively. This indicated a rapid metabolism of GG followed by quick elimination from the body. An observed higher in vivo clearance indicated that GG was a poor bioavailable compound and the reduced AUC for the plasma profile was probably due to the rapid elimination of GG from the central compartment. The in vivo pharmacokinetic study was performed taking a single dose through PO and IV administration, which is a better representation for the pilot study.

A good metabolic stability in liver microsomes, optimum Caco-2 permeability, and pharmacokinetic profile in preclinical species are the major characteristics for a potential and safe drug molecule that could be further extrapolated in humans before clinical trials. Here, we have tried to establish the in vitro and in vivo pharmacokinetics, permeability, and efflux concerns for GG, and correlate its in vitro findings with that of the in vivo data. To conclude, it will be interesting to mention that although we have observed a good in vitro - in vivo correlation of GG, one of the major phytomarkers of $G$. sylvestre, it probably possesses poor drug-like properties in terms of metabolic stability and permeability, at least with the limits of our experimental conditions. Further studies are required to investigate the contribution of different transporters in absorption and efflux as well as extrahepatic factors/metabolism that may have reduced the overall bioavailability of GG in our study.

\section{Materials and Methods}

\section{$\nabla$}

\section{Chemicals and reagents}

HPLC grade water (resistivity of $18 \mathrm{M} \Omega \times \mathrm{cm}$ ) generated from a Milli Q water purification system, methanol, and acetonitrile (HPLC grade) were purchased from JT Baker. DMSO ( $\geq 99.9 \%)$, $\mathrm{KH}_{2} \mathrm{PO} 4(\geq 99 \%), \mathrm{K}_{2} \mathrm{HPO}_{4}(\geq 99 \%), \mathrm{MgCl}_{2}$ hexahydrate $(\geq 99 \%)$, atenolol ( $\geq 98 \%)$, furosemide $(\geq 98 \%)$, carbamazepine $(\geq 98 \%)$, domperidon ( $\geq 98 \%)$, desipramine $(\geq 98 \%)$, verapamil $(\geq 99 \%)$, metoprolol ( $\geq 98 \%$ ), dexamethasone $(\geq 97 \%)$, quinidine $(\geq 80 \%)$, and LY were purchased from Sigma, and RLMs were from Invitrogen. NADP ( $\geq 98 \%$ ), Glucose-6-phosphate (99\%) and glucose-6phosphate dehydrogenase were from SRL, and GG (>95\%) was from Natural Remedies. The Caco-2 cell layer from ATCC, apical and basal plates from $\mathrm{BD}$, and all cell culture reagents and media were obtained from Gibco BRL Life Technology. All flasks were obtained from Coring Science Product Division, and other chemicals were of analytical grade.

\section{Instrumentation and chromatographic conditions}

The liquid chromatography part consisted of an LC-20ADvp pump, system controller, CTC PAL (HTS) autosampler, and tandem mass spectrometer with an ESI source in API-4000. Detection and quantification were performed using Analyst 1.4 .2 software.

Analyte separation was achieved on a Luna $\mathrm{C}_{18}$ column $(2 \times$ $30 \mathrm{~mm}, 5 \mu \mathrm{m})$ with a Security Guard $C_{18}$ guard column $(4 \times$ $3.0 \mathrm{~mm}$ i.d.) from Phenomenex with a flow rate of $0.8 \mathrm{~mL} / \mathrm{min}$. The mobile phases were $0.1 \%$ formic acid in water $(A)$ and a mixture of acetonitrile, methanol, and water at 50:30:20 with $0.1 \%$ acetic acid (B). The gradient elution program was as follows: first $72 \mathrm{~s}$ of only A for washing and then $84 \mathrm{~s}$ for the gradient up to 
$100 \% \mathrm{~B}$; this was continued for the next $60 \mathrm{~s}$ and the total run time was $4.0 \mathrm{~min}$.

Samples after the Caco-2 and RLM study were analyzed in LC-MS/MS using a Luna phenyl hexyl cartridge $(2 \times 10 \mathrm{~mm}$, $5 \mu \mathrm{m}$ ) with a flow rate of $0.80 \mathrm{~mL} / \mathrm{min}$. The mobile phases were water containing $0.1 \% \mathrm{v} / \mathrm{v}$ formic acid (A) and a mixture of acetonitrile and water $(80: 20)$ containing $0.1 \%$ formic acid and $2 \mathrm{mM}$ ammonium acetate (B).

\section{In vitro kinetic study using rat liver microsomes}

GG along with the quality control compounds desipramine, metoprolol, and verapamil were incubated for $0,5,10,20,30$, and $60 \mathrm{~min}$ in a temperature controlled water bath of $37^{\circ} \mathrm{C}$ at a $1 \mu \mathrm{M}$ concentration in the absence of the blank and with another 60 min sample without the cofactor (WC) for chemical degradation control. We followed the experimental procedure/protocol that has already been reported, with minute modifications [22]. Briefly, $100 \mu \mathrm{L}$ of incubation mixture contained RLM $(0.5 \mathrm{mg} /$ $\mathrm{mL})$, NADP (1.3 mM), glucose-6-phosphate (3.3 mM), and glucose-6-phosphate dehydrogenase $(0.4 \mathrm{U} / \mathrm{mL})$ containing $\mathrm{MgCl}_{2}$ (3.3 $\mathrm{mM}$ ) solution in phosphate buffer $\mathrm{pH}$ 7.4. All reactions were started by the addition of NRS in a 96 deep-well plate and were carried out for the abovementioned time points. The reaction was terminated by the addition of $300 \mu \mathrm{L}$ of ice-cold acetonitrile and mixed, followed by centrifugation at $4000 \mathrm{rpm}$ for $15 \mathrm{~min}$ at $15^{\circ} \mathrm{C}$. One hundred and twenty $\mu \mathrm{L}$ of supernatant were diluted with $120 \mu \mathrm{L}$ of water, and $25 \mu \mathrm{L}$ were injected into the LC-MS/MS. Time on the $\mathrm{X}$ axis and $\ln$ (area of analyte) on the Y axis were plotted in a semi-log plot to calculate the slope. Intrinsic $\mathrm{T}_{1 / 2}$ was calculated by dividing -0.693 with the slope. In vitro $\mathrm{CL}_{\mathrm{int}}$ was scaled to an in vivo $\mathrm{CL}_{\text {int }}$ (in units of $\mathrm{mL} / \mathrm{min} / \mathrm{kg}$ ) using microsomal protein ( $\mathrm{mg} / \mathrm{g}$ of liver) and average liver weight ( $\mathrm{g}$ of liver/ $\mathrm{kg}$ of body weight) according to the following formula:

$\mathrm{CL}_{\text {int }}^{\prime}=\left(0.693 /\right.$ in vitro $\left.\mathrm{T}_{1 / 2}\right) \times(\mathrm{mL}$ of incubation volume $/ \mathrm{mg}$ of microsomal protein $) \times(45 \mathrm{mg}$ microsomal protein $/ g$ of liver $) \times$ (20 $\mathrm{g}$ of liver $/ \mathrm{kg}$ of body weight)

a: 20 and $45 \mathrm{~g}$ of liver $/ \mathrm{kg}$ of body weight were used for human and rat respectively [19].

\section{Caco-2 permeability study (A-B and B-A)}

$A$ to $B$ cell plating and culture: The Caco- 2 cell line was obtained from ATCC and cells were seeded at $6.3 \times 10^{4}$ cells $/ \mathrm{cm}^{2}$ and grown in a medium containing Dulbecco's modified Eagle's medium (DMEM) comprised of $4.5 \mathrm{~g} / \mathrm{L}$ glucose and supplemented with $10 \%(\mathrm{v} / \mathrm{v})$ fetal bovine serum (FBS), $1 \%(\mathrm{v} / \mathrm{v})$ glutamine, penicillin $(100 \mathrm{U} / \mathrm{mL})$, streptomycin $(100 \mu \mathrm{g} / \mathrm{mL})$, and $1 \%(\mathrm{v} / \mathrm{v})$ Minimum Essential Medium (MEM) nonessential amino acids. Cultures were maintained at $37^{\circ} \mathrm{C}$ in an atmosphere of $95 \%$ air and $5 \%$ $\mathrm{CO}_{2}$ with controlled humidity. The medium was changed in every 2-3 days. Routine passing of all cell stocks was carried out in $75 \mathrm{~cm}^{2}$ flasks, and experiments were done on passages \#25-30. Sevnty-five $\mu \mathrm{L}$ of $2.5 \times 10^{5}$ cells $/ \mathrm{mL}$ and $40 \mathrm{~mL}$ of media were transferred to the apical wells and to the feeder tray, respectively. The plates were placed in an incubator $\left(37^{\circ} \mathrm{C}, 5 \% \mathrm{CO}_{2}\right.$, and controlled humidity). The first media change was given between 40-72 h and cells were grown for 21 days with a media change every alternate day.

$B$ to A cell plating and culture: $25 \mu \mathrm{L}$ of $7.5 \times 10^{5}$ cells $/ \mathrm{mL}$ were transferred to the bottom side (keeping the plate upside down) of apical wells. The plate (upside down position) was kept in an incubator $\left(37^{\circ} \mathrm{C}, 5 \% \mathrm{CO}_{2}\right.$, and controlled humidity) for $2 \mathrm{~h}$. The plate was turned right side up. Seventy-five $\mu \mathrm{L}$ of media/well to the apical plate and $40 \mathrm{~mL}$ of media to the feeder tray were added.

\section{Transport study}

Permeability assay $A$ to $B$ : The apical wells were washed with buffer pH 6.5 and basal wells washed with buffer pH 7.4. Two hundred and fifty $\mu \mathrm{L}$ of buffer $\mathrm{pH} 7.4$ /well were added to the basal plate. Seventy-five $\mu \mathrm{L}$ of GG, atenolol, furosemide, carbamazepine, and verapamil solutions $(2 \mu \mathrm{M})$ in buffer $\mathrm{pH} 6.5$ were added to the apical wells $(\mathrm{n}=6)$.

Permeability assay $B$ to $A$ : The apical wells were washed with buffer $\mathrm{pH} 7.4$ and basal wells with buffer pH 6.5. Two hundred and fifty $\mu \mathrm{L}$ of buffer $\mathrm{pH} 6.5 /$ well were added to the basal plate. Seventy-five $\mu \mathrm{L}$ of $\mathrm{GG}$, domperidon, furosemide, carbamazepine, quinidine, and verapamil solutions $(2 \mu \mathrm{M})$ in buffer $\mathrm{pH} 7.4$ were added to the apical wells $(n=6)$. The apical plate was placed on to the basal plate with a lid to prevent evaporation. The assembly was incubated at $37^{\circ} \mathrm{C}$ for $2.5 \mathrm{~h}$ under $95 \%$ air and $5 \% \mathrm{CO}_{2}$ with controlled $\mathrm{RH}$. The apical plate was separated after incubation and aliquots from the acceptor wells were taken, diluted, and quantified by LC-MS/MS along with the initial donor samples.

\section{Membrane integrity}

To optimize the membrane integrity of the Caco- 2 monolayer, the TEER was determined during the cell culture. A little increase in the TEER value was found between days 15 and 20. Another membrane integrity test post the Caco- 2 experiment was performed using lucifer yellow by fluorimetry. Solutions in the apical wells were discarded by inverting the plate and soaking them on tissue paper very carefully. Phosphate buffer pH 7.4 $250 \mu \mathrm{L} /$ well was added to the basal plate. Seventy-five $\mu \mathrm{L}$ of LY $(0.1 \mathrm{mg} /$ $\mathrm{mL}$ ) in buffer $\mathrm{pH} 7.4$ per well were added to the apical plate. The apical plate was placed on to the basal plate with a lid. The assembly was incubated at $37^{\circ} \mathrm{C}$ for $1 \mathrm{~h}$ under $5 \% \mathrm{CO}_{2}$ and $95 \%$ air. The apical plate was separated after incubation, and $100 \mu \mathrm{L}$ of solution from the basal wells were transferred for the fluorescence (Ex: $432 \mathrm{~nm}, \mathrm{Em}$ : $530 \mathrm{~nm}$ ) measurement. A fluorescence of $100 \mu \mathrm{L}$ buffer pH 7.4 only and $100 \mu \mathrm{L} \mathrm{LY}(0.1 \mathrm{mg} / \mathrm{mL})$ were also measured.

\section{Animal study}

Pharmacokinetic study: The experiments were conducted using male Wistar rats under the care and use of laboratory animals in accordance with the guidelines prescribed by the Institutional Ethical Committee (constituted under the guidelines of Committee for the Purpose of Control and Supervision of Experiments on Animals, CPCSEA, Reg. No. 367). The study was approved by the ethical committee on $11 / 12 / 2014$ and the approval number is AEC/PHARM/1407/2014. Animals were acclimatized individually in a cage under a $12 / 12$-h light dark cycle, $22 \pm 2{ }^{\circ} \mathrm{C}$ temp, $50 \pm 20 \%$ RH 5 days prior to the studies and maintained on an $18 \%$ casein-containing semisynthetic diet with free access to food and water. Pharmacokinetic studies with GG were carried out in male (180-200 g) Wistar rats after oral and intravenous administration of GG at a dose of $5 \mathrm{mg} / \mathrm{kg}$ and $1 \mathrm{mg} / \mathrm{kg}$, respectively. A solution formulation of GG was made in $10 \%$ DMSO, 30\% propylene glycol, and the rest was $5 \%$ glucose solution with a dose volume of $5 \mathrm{~mL} / \mathrm{kg}$ for oral and $2 \mathrm{~mL} / \mathrm{kg}$ for IV. Animals were divided into two groups - Gr-I $(n=6)$ for oral and Gr-II $(n=6)$ for IV. About $130 \mu \mathrm{L}$ of whole blood were collected at predetermined time points (Pre-dose, 0.08, 0.25, 0.5, 1, 2, 4, 8, and $24 \mathrm{~h}$ ) via jugular 
vein cannulation, and normal saline solution was supplemented in each time point after sample collection. The collected samples were centrifuged at $2500 \mathrm{rpm}$ for $10 \mathrm{~min}$ at $4^{\circ} \mathrm{C}$ and the collected plasma was stored at $-70^{\circ} \mathrm{C}$ until bioanalysis.

Method validation: The validation of the bioanalytical method in plasma was carried out for selectivity, linearity, precision, accuracy, recovery, matrix effect, and stability according to the principles of the Food and Drug Administration [13] industry guide. An 11-point calibration curve covering a range of $0.98-1000 \mathrm{ng} /$ $\mathrm{mL}$ of GG was prepared in duplicate and analyzed in three different runs on three separate days with six replicates of the LLOQ $(0.98 \mathrm{ng} / \mathrm{mL})$, LQC $(2.94 \mathrm{ng} / \mathrm{mL})$, MQC $(400 \mathrm{ng} / \mathrm{mL})$, and HQC $(800 \mathrm{ng} / \mathrm{mL})$ samples. The curves were fitted using a linear regression method with weighting $1 / \mathrm{x}^{2}$.

The selectivity, specificity, and intraday and interday precision and accuracy of the method were assessed. The extraction recovery (ER) and matrix effect of GG after protein precipitation was determined at three concentration levels, and the extraction recovery of IS was also carried out at a single $(70 \mathrm{ng} / \mathrm{mL})$ concentration. The ME was evaluated in the present study as proposed by Matuszewski et al. [23].

Recovery $(\%)=($ peak area of the extracted analyte $\times 100 /$ peak area of the non-extracted analyte mixed with blank matrix extract)

$\mathrm{ME}(\%)=\{1-($ response for post-extraction spiked drug $) /($ response in solvent $)\} \times 100$

The stability of GG was evaluated as part of the method validation. The processed sample stability in the autosampler at $4^{\circ} \mathrm{C}$ for $12 \mathrm{~h}$, stability of GG in the biomatrix after $8 \mathrm{~h}$ exposure on the bench-top, long-term stability (30 days) of the spiked QC samples stored at $-70.00^{\circ} \mathrm{C}$, and freeze-thaw stability ( 3 cycles) were evaluated.

The standard stock solution of GG (analyte) and dexamethasone (IS) were prepared in DMSO $(2.00 \mathrm{mg} / \mathrm{mL})$ for each. Then an intermediate stock $(100.00 \mu \mathrm{g} / \mathrm{mL})$ for GG and IS were prepared in DMSO. The working stock solutions 50000.00, 25000.00, $12500.00,6250.00,3125.00,1562.50,781.25,390.63,195.31$, 97.66 , and $48.83 \mathrm{ng} / \mathrm{mL}$ for the calibration curve (CC), and $146.48,20000.00$, and $40000.00 \mathrm{ng} / \mathrm{mL}$ for QCs were prepared from intermediate stock in DMSO. CC and QC samples were prepared by spiking $2 \mu \mathrm{L}$ from the working stock to $98 \mu \mathrm{L}$ blank matrix to get final concentrations of $1000.00,500.00,250.00$, $125.00,62.50,31.25,15.63,7.81,3.91,1.95$, and $0.98 \mathrm{ng} / \mathrm{mL}$ and 2.94 (LQC), 400.00 (MQC), and 800.00 (HQC) $\mathrm{ng} / \mathrm{mL}$ for the CC and QC samples. Five $\mu \mathrm{L}$ of $350.00 \mathrm{ng} / \mathrm{mL}$ (IS) were spiked in each sample. All standard and IS stock solutions were stored in polypropylene vials at $2-8^{\circ} \mathrm{C}$ for further use.

Sample preparation for plasma: All plasma samples along with linearity and QC samples were analyzed using the validated LC-MS/MS method. The plasma sample aliquot $(30 \mu \mathrm{L})$ was taken into a V-bottom shallow 96-well plate and direct precipitation of the matrix was done by adding an ice-cold mixture $(70 / 30, v / v)$ of acetonitrile and methanol ( $3 \times$ sample volume). The mixture was mixed in a thermomixer for $8 \mathrm{~min}$ and centrifuged at $4000 \mathrm{rpm}$ for $15 \mathrm{~min}$ at $15^{\circ} \mathrm{C}$. Sixty $\mu \mathrm{L}$ of clear supernatant was mixed with $50 \mu \mathrm{L}$ of water, and $20 \mu \mathrm{L}$ of aliquot was injected into the LCMS/ MS.

Pharmacokinetic analysis: Pharmacokinetic parameters were calculated from the plasma concentration data following oral and IV administration ( $\bullet$ Fig. 1 ) by a noncompartmental method using WinNonlin 6.3. The area under the plasma concentration-time curve, $\mathrm{AUC}_{0-\text { tlast }}$, was calculated from time $0 \mathrm{~h}$ to the last quanti- fiable time point by the linear trapezoidal method. The time at which $C_{\max }$ was achieved $\left(T_{\max }\right)$, the apparent maximum plasma concentration $\left(\mathrm{C}_{\max }\right)$ and the terminal elimination rate constant $\left(\mathrm{K}_{\mathrm{el}}\right)$, terminal half-life $\left(\mathrm{T}_{1 / 2}\right)$, clearance $(\mathrm{CL})$, volume of distribution $\left(\mathrm{V}_{\mathrm{d}}\right)$, total exposure $\mathrm{AUC}_{0-\text { last }}$, and $\mathrm{AUC}_{0-\alpha}$ were determined (O Table 3).

\section{Supporting information}

Mass spectrometry and chromatography data of GG and dexamethasone, as well as intraday and interday precision and accuracy data of GG, and stability data are available as Supporting Information.

\section{Acknowledgements}

$\nabla$

We express our sincere thanks to AICTE-RPS, New Delhi, India, and UGC UPE-II for providing financial support for this study.

\section{Conflict of Interest}

$\nabla$

The authors declare that there is no conflict of interest.

\section{References}

1 Mitra SK, Gopumadhavan S, Muralidhar TS, Anturlikar SD, Sujatha MB. Effect of D-400 herbomineral preparation on lipid profile glycated haemoglobin and glucose tolerance in streptozotocin induced diabetes in rats. Indian J Exp Biol 1995; 33: 798-800

2 Ye WC, Zhang Q Liu X, Che C, Zhao S. Oleanane saponins from Gymnema sylvestre. Phytochemistry 2000; 53: 893-899

3 Bakrudeen AAH, Rao AS, Rao MV, Tahil RM. Different wavelengths light to induce physiological changes callus for the biosynthesis of gymnemic acid in Gymnema sylvestre. Food Tech 2012; 23: 31-34

4 Kanetkar PV, Singhal RS, Laddha KS, Kamat MY. Extraction and quantification of gymnemic acids through gymnemagenin from callus cultures of Gymnema sylvestre. Phytochem Anal 2006; 17: 409-413

5 Trivedi PD, Pundarikakshudu K, Shah K. A validated reverse phase liquid chromatographic method for quantification of gymnemagenin in the Gymnema sylvestre R. Br. leaf samples, extract and market formulation. IJASE 2011; 9: 25-31

6 Tiwari P, Mishra BN, Sangwan NS. Phytochemical and pharmacological properties of Gymnema sylvestre: an important medicinal plant. Biomed Res Int 2014; 2014: 830285

7 Kerns EH, Di L. Drug-like properties: concepts, structure design, and methods - from ADME to toxicity optimization. Amsterdam: Academic Press; 2008: 136-164

8 Obach RS, Baxter JG, Liston TE, Silber BM, Jones BC, McIntyre F, Rance DJ, Wastall $P$. The prediction of human pharmacokinetic parameters from preclinical and in vitro data. J Pharmacol Exp Ther 1997; 283: 46-58

9 Chetan SK, Natalie DE, Tushar SG, Paul OG, Thomas CD. Evaluation of drug P-glyprotein-mediated renal drug interaction in an MDR1-MDCK model. Pharmacotherapy 2003; 23: 436-442

10 Artursson P, Karlsson J. Correlation between oral absorption in human and apparent drug permeability coefficients in human intestinal epithelial (Caco-2) cells. Biochem Biophys Res Commun 1991; 175: 880885

11 Grès MC, Jullian B, Bourrié M, Meunier V, Roques C, Berger M, Boulenc X, Berger Y, Fabre G. Correlation between oral drug absorption in human and apparent drug permeability in TC-7 cells, a human epithelial intestinal cell line: comparison with the parental Caco-2 cell line. Pharm Res 1998; 15: 726-733

12 Bhagyashree K, Ankur G, Dada P, Laxman K, Shirish J, Ismail M, Basavan $D$. Determination of gymnemagenin in rat plasma using high-performance liquid chromatography-tandem mass spectrometry: application to pharmacokinetics after oral administration of Gymnema sylvestre extract. Biomed Chromatogr 2013; 27: 669-675

13 Food and Drug Administration of the United States. Guidance for Industry - Bioanalytical Method Validation; May 2001. Available at http:// 
www.fda.gov/downloads/Drugs/Guidances/ucm070107.pdf. Accessed March 18, 2014

14 Hazra A, Mondal C, Chakraborty D, Halder AK, Bharitkar YP, Mondal SK, Banerjee S, Jha T, Mondal NB. Towards the development of anticancer drugs from andrographolide: semisynthesis, bioequivalence, QSAR analysis and pharmacokinetic studies. Curr Top Med Chem 2015; 15 : 1013-1026

15 Kratz JM, Teixeira MR, Koester LS, Simões CM. An HPLC-UV method for the measurement of permeability of marker drugs in the Caco-2 cell assay. Braz J Med Biol Res 2011; 44: 531-537

16 Garberg P, Eriksson P, Schipper N, Sjöström B. Automated absorption assessment using Caco-2 cell cultured on both sides of polycarbonate membranes. Pharm Res 1999; 16: 441-445

17 Fagerholm U, Johansson M, Lennernäs $H$. Comparison between permeability coefficients in rats and human jejunum. Pharm Res 1996; 13: 1336-1342

18 Houston JB, Kenworthy KE, Galetin A. Typical and atypical enzyme kinetics. In: Lee JS, Obach RS, Fisher MB, editors. Drug metabolizing en- zymes: cytochrome P450 and other enzymes in drug discovery and development. Boca Raton, FL: CRC Press; 2003: 211-254

19 Obach RS. Prediction of human clearance of twenty-nine drugs from hepatic microsomal intrinsic clearance data: an examination of in vitro half-life approach and nonspecific binding to microsomes. Drug Metab Dispos 1999; 27: 1350-1359

20 Polli JE, Wring SA, Humphreys JE, Huang L, Morgan JB, Webster LO, Serabit-Singh CO. Rational use of in vitro P-glycoprotein assays in drug discovery. J Pharmacol Exp Ther 2001; 299: 620-628

21 Higers AR, Conradi RA, Burton PS. Caco-2 cell monolayers as a model for drug transport across the intestinal mucosa. Pharm Res 1990; 7: $902-$ 910

22 Di L, Kerns EH, Hong Y, Kleintop TA, McConnell OJ, Huryn DM. Optimization of a higher throughput microsomal stability screening assay for profiling drug discovery candidates. J Biomol Screen 2003; 8: 453-462

23 Matuszewski BK, Constanzer ML, Chavez-Eng CM. Strategies for the assessment of matrix effect in quantitative bioanalytical methods based on HPLC-MS/MS. Anal Chem 2003; 75: 3019-3030 